\title{
Dinâmica do poder em $O$ alienista
}

Jaison Luis Crestani

$\mathrm{D}_{3}^{\mathrm{B}}$ EPOIS do livro clássico da bibliografia machadiana, Apresentação de Machado de Assis (1987), Ivan Teixeira - full professor da Universidade do Texas, em Austin, e professor livre-docente de Cultura e Literatura Brasileira da Escola de Comunicações e Artes (ECA), da Universidade de São Paulo (USP) apresenta mais uma obra de referência fundamental para os estudos machadianos: O altar e o trono: dinâmica do poder em $O$ alienista. Elaborado originalmente como tese de livre-docência para a USP, o trabalho de Teixeira desafia os conceitos estabelecidos em torno da narrativa machadiana e a compreensão tradicional da atividade literária do autor.

Afirmando-se como obra provocadora, empenhada na revisão conceitual e na renovação crítica da bibliografia machadiana, $O$ altar e o trono destaca-se, inicialmente, pela ruptura em relação à tendência da tradição crítica de valorizar a condição universal do escritor e a projeção de sua escrita para a posteridade. Em sua apreciação questionadora, Teixeira evidencia o empenho dessa tradição na demonstração da "superioridade intrínseca" do autor e na identificação do periódico feminino $A$ Estação, no qual $O$ alienista foi originalmente publicado, com a ideia de "irrelevância cultural". Dissocia-se, assim, a ficção machadiana de seu contexto de produção e de circulação de modo a caracterizar a colaboração do escritor no periódico como uma simples "estratégia de sobrevivência".

Contrapondo-se a essa tendência dominante dos estudos machadianos, $\mathrm{O}$ altar e o trono propõe uma análise da atua- ção de Machado de Assis como "homem de imprensa, envolvido com os debates e linguagens da época, com a audiência e outras circunstâncias do periódico feminino para o qual escreveu a novela" (p.15). Desse modo, concebendo a literatura como resultado do "intercâmbio da fala do artista com os diversos discursos de seu tempo" (p.29), o livro busca integrar o autor à poética cultural da época e às diretrizes editoriais da revista A Estação, cujos valores o escritor ajudou a construir e com os quais se identifica intelectualmente.

$\mathrm{Na}$ análise das confluências discursivas entre a novela e o periódico, Teixeira averigua a contribuição decisiva da revista para o "desenvolvimento do repertório técnico e temático do escritor”, como também para a "constituição de sua imagem pública e de seus valores" (p.48). Por meio de um minucioso exame do conjunto de matérias publicado pela revista, o crítico defende a hipótese de que Machado de Assis não foi apenas um colaborador da "Parte Literária", mas também o seu editor responsável. A constatação desse possível compromisso com a diretriz editorial do periódico conduz a uma desconstrução da imagem do escritor instituída pela crítica marxista, que enfatiza insistentemente a hostilidade crítica do autor em relação à classe dominante. Nessa linha, Ivan Teixeira relativiza também a interpretação da "volubilidade do estilo machadiano" na sua associação unilateral com a sátira à suposta inconstância das elites - viés de leitura instituído pelos estudos de Roberto Schwarz. Para o autor de $O$ altar 
e o trono, essa apropriação do princípio fragmentário resultaria mais propriamente da convivência com a dinâmica do jornal, cuja diagramação pressupõe o fracionamento das matérias publicadas.

Essa visão dessacralizada do escritor permite redefinir também a contribuição de $A$ Estação para a transformação cultural do país. O expressivo investimento da revista no acabamento gráfico, que confere uma sofisticada eficiência visual às suas páginas, agregado à disponibilização de um material artístico apurado e à inserção da mulher no processo de conscientização política, torna o periódico um partícipe eminente da mudança que se opera no pensamento e nas práticas sociais do Segundo Reinado, tanto no nível jornalístico quanto no plano político, social e literário. Portanto, em vez da denúncia agressiva, Machado participaria da conviç̧ão retórica dessa transformação, empenhando-se no projeto de ilustração intelectual da elite feminina brasileira e de formação de uma percepção crítica da conjuntura política e social do Segundo Reinado. Como editor do suplemento literário de $A E s^{-}$ tação, Machado de Assis figuraria como espírito orientador de um projeto estético comprometido com a "reforma do gosto antirromântico" e com a afirmação e consolidação de um repertório afinado ao presumível equilíbrio da estética realista e de suas variantes modernas, como o parnasianismo, promovido também pelos demais colaboradores da revista, especialmente Olavo Bilac, Raimundo Correia e Alberto de Oliveira.

$\mathrm{Na}$ opinião de Teixeira, não se pode desconsiderar também a possibilidade de a literatura machadiana ter participado do processo de construção da aura de sociabilidade necessária à comercialização de produtos que remetem à ideia de civilização e modernidade. Nesse sentido, o crítico julga pertinente a hipótese de que a apropriação machadiana de autores das literaturas inglesa e francesa filiase à tendência internacionalista do periódico de alimentar o interesse da elite pela identificação cultural com os modelos europeus. Dessa forma, a assimilação de técnicas de Swift, Sterne, La Bruyère e Teofrasto, identificadas pelo crítico na composição de $O$ alienista, se ajustaria a uma prática coletiva que considerava a incorporação de padrões europeus como uma forma de "evitar o provincianismo regionalista de certas tendências da sociedade e da arte romântica" (p.70).

Nessa relação dinâmica entre a revista e o escritor, identifica-se uma estratégia editorial empenhada em atribuir indiretamente respeitabilidade artística ao periódico, valendo-se, para tanto, da divulgação da ideia de que seu principal colaborador se impunha como "modelo de bom gosto, de boas maneiras, de humor civilizado e de domínio técnico sobre os mistérios da ficção e da língua portuguesa" (p.116). A presença ostensiva do autor como assunto nas páginas do periódico feminino, por meio de resenhas elogiosas, notícias favoráveis à sua imagem pública e apreciações aprovadoras de sua produção literária, traduz a significativa contribuição da revista $A$ Estação na instituição do conceito $M a$ chado de Assis. Os estudos de sua obra divulgados pela revista - elaborados, talvez, pelo próprio escritor - estabelecem as linhas gerais que ainda hoje orientam a história da crítica machadiana.

Essa reciprocidade legitimadora explicaria, consequentemente, a opção machadiana pela alegoria moralizante, em lugar da denúncia agressiva, afinando-se 


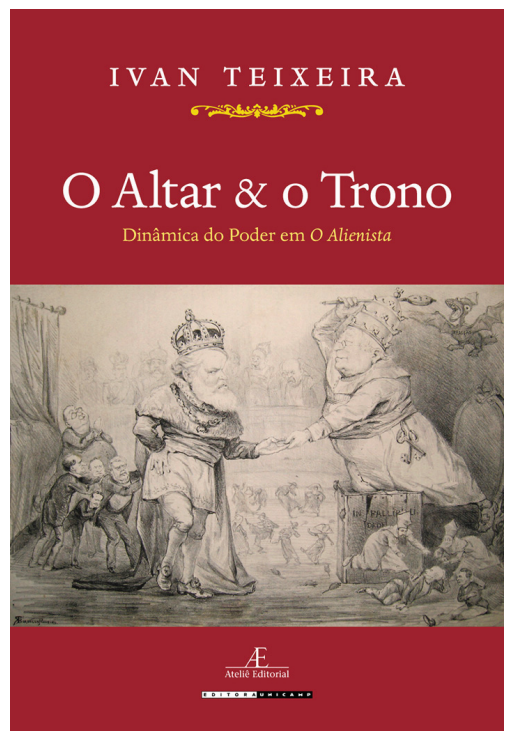

TEIXEIRA. I. O altar e o trono: dinâmica do poder em $\mathrm{O}$ alienista. São Paulo: Ateliê Editorial, Editora da Unicamp, 2010.

assim ao liberalismo moderado da revista. Para Ivan Teixeira, uma sociedade como a do Rio de Janeiro oitocentista não poderia aproximar-se do modelo de civilização europeia se desfavorecesse "o surgimento e a consolidação de artistas que, pela crítica, legitimassem as instituições e os valores das camadas dirigentes locais", sobretudo aquelas comprometidas com a modernização do país.

A minuciosa análise do perfil editorial de $A$ Estação, elaborada por Ivan Teixeira com um acurado exame de sua iconografia, permite perceber que o periódico opera por insinuações, sutilezas, contradições e sinuosidades na formulação do sentido e do propósito de suas publicações. Esses meandros inquietantes revelam-se especialmente na combinação da defesa da beleza espiritual com a venda de produtos para o corpo: "para vender moda, o jornal critica o mau uso da própria moda" (p.154). Requisitando a autocrítica da leitora, a revista investe na construção diferenciada de um modelo de civilidade elegante, que denuncia o exagero e a ostentação para priorizar um conceito de elegância fundamentado na moderação, na cultura e na inteligência. É nesse ponto que a sátira de $O$ alienista aos desvios da conduta apregoada como "equilibrada" dialoga mais enfaticamente com as matérias do periódico. Na representação caricatural desses vícios e extravagâncias, Ivan Teixeira vislumbra uma possível apropriação machadiana da técnica de construção da personagem praticada em Os caracteres, de Teofrasto, que Machado teria lido na versão francesa de La Bruyère, presente em sua biblioteca.

$\mathrm{Na}$ análise da composição narrativa e temática de $O$ alienista, Ivan Teixeira prossegue igualmente na contracorrente da crítica machadiana, relativizando a importância atribuída ao tema da loucura e à sátira das teorias cientificistas. Nesse âmbito, o crítico questiona a tradição de leitura da novela que acata o boato do padre como atestado da loucura de Bacamarte, consumada desde o início da narrativa. Para Teixeira, essa visão é manipulada pelos artifícios que a Igreja opera na disputa pelo poder. Desse modo, o crítico investe numa abordagem que considera $O$ alienista como "imitação burlesca da história do mundo" e denúncia irônica da "disputa pelo poder no processo de formação da cidade". Sob essa perspectiva, a narrativa é entendida como intervenção artística de Machado de Assis nas controvérsias e dissidências entre a Igreja e o Estado ocorridas por ocasião da Questão Religiosa (1872-1875) e como paródia das 
convicções políticas e científicas que ambicionavam a solução do problema da loucura.

De acordo com a interpretação proposta em $O$ altar e o trono, para elaborar essa representação paródica, o autor utilizou-se de recursos próprios da tradição luciânica ou da sátira menipeia e da poética da forma livre. Na opinião de Ivan Teixeira, a opção machadiana pelo emprego da sátira menipeia e da poética da forma livre nas narrativas remetidas à revista $A$ Estação "associa-se à necessidade dialética de ajustar o texto ao veículo a que se destinava", fazendo-o "parecer com o jornal, com o leitor e com o tempo de sua produção" (p.141). Dessa forma, fundamentadas na extravagância fantasiosa, no humor disparatado e no pessimismo irônico, a menipeia e a forma livre promovem frequentes exageros e contínuas caricaturas, que resultam no humor irreverente, cujo dispositivo técnico mais importante será a paródia ou imitação burlesca de estruturas consagradas da cultura. Por meio da paródia do estilo historiográfico, a novela machadiana afirma-se como "variante verbal" do amplo discurso caricatural, promovido pela imprensa da época, segundo o qual o poder internacional da Igreja pretendia sobrepor-se ao do imperador do Brasil.

$\mathrm{Na}$ apropriação machadiana dos procedimentos da sátira menipeia, Ivan Teixeira analisa as conexões que se evidenciam com a tópica camoniana do desconcerto do mundo e com a lógica do paradoxo, que institui o absurdo como equilíbrio, conforme se observa na composição das obras de Swift, $A$ Modest Proposal e A Serious and Useful Scheme to Make na Hospital for Incurables.
Outra referência intertextual examinada por Ivan Teixeira é a obra de Edgar Allan Poe, especialmente o conto "The system of Dr. Tarr and Prof. Fether", que, assim como $O$ alienista, opera uma inversão de valores, marcada pelo descompasso entre a relatividade da definição de loucura e a certeza dos métodos de tratamento, do qual decorre o efeito humorístico de ambas as narrativas. Rechaçando a noção de ascendência hierárquica de um autor sobre o outro, Teixeira aponta também a confluência que se observa na valorização do exercício da brevidade, que seria condicionada pela prática jornalística que impõe um ajustamento ao espaço circunscrito disponível em cada número do veículo.

Como se observa, $O$ altar e o trono apresenta uma abordagem multíplice do processo de criação de $O$ alienista, agregando o exame da materialidade da publicação e de sua vinculação dinâmica com o perfil editorial do periódico, a análise da maneira como se processa a intervenção artística em assuntos polêmicos de seu tempo, e um amplo estudo comparativo com as possíveis fontes internacionais incorporadas pelo autor na composição de sua narrativa. Transcendendo a especificidade da narrativa, o trabalho de Ivan Teixeira se impõe no campo dos estudos machadianos como instrumento de renovação crítica da compreensão da atividade literária do escritor, relativizando as certezas estabelecidas e requisitando a reabertura de questões supostamente equacionadas pela tradição crítica.

Jaison Luis Crestani é doutorando na Universidade Estadual Paulista "Júlio de Mesquita Filho" (Unesp), campus de Assis. @-jaisoncrestani@hotmail.com 